\title{
Large-scale planetary disturbances in stratospheric temperature at high-latitudes in the southern summer hemisphere
}

\author{
M. G. Shepherd ${ }^{1}$ and T. Tsuda ${ }^{2}$ \\ ${ }^{1}$ Centre for Research in Earth and Space Science, York University, Toronto, Canada \\ ${ }^{2}$ Research Institute for Sustainable Humanosphere, Kyoto University, Kyoto, Japan
}

Received: 18 June 2008 - Published in Atmos. Chem. Phys. Discuss.: 27 August 2008

Revised: 27 November 2008 - Accepted: 23 July 2008 - Published: 17 December 2008

\begin{abstract}
The global structure and propagation of largescale (periods $>5$ days) waves in the Southern Hemisphere summer (December 2006-February 2007) at $60^{\circ} \mathrm{S}-75^{\circ} \mathrm{S}$ latitude are examined using temperature data from GPS radio occultation measurements by COSMIC/FORMOSAT 3 satellite constellation at $20 \mathrm{~km}$ and $30 \mathrm{~km}$ altitude. Spectral analysis has revealed eastward propagating planetary scale perturbations with wavenumbers 1 and 2 and periods of 10 , 16 and 23 days, and stationary waves with wavenumbers 1 and 2 . The results obtained show a very dynamically active Antarctic summer stratosphere. The novel aspect of the work is in the use of the GPS COSMIC data providing multiple local times each day, thus allowing large-scale wave analysis at high Southern latitudes and revealing planetary wave activity not normally observed in summer, but more consistent with late winter and spring conditions in the stratosphere.
\end{abstract}

\section{Introduction}

Large-scale planetary waves determine the dynamic temperature and wind regimes of the atmosphere. In the Southern Hemisphere these large-scale waves have a predominant eastward direction of propagation (e.g. Randel and Newman, 1998 and references therein). Temperature observations from the Selective Chopper Radiometer (SCR) on the Nimbus satellites revealed intense wave activity at high Southern latitudes in late winter and spring consisting of oscillations predominantly with a wavenumber 1 (wave 1) identified as a stationary wave, accompanied by an eastward propagating oscillation with wavenumber 2 (wave 2) (Chapman et al., 1974;

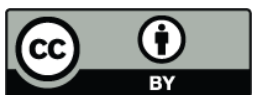

Correspondence to: M. G. Shepherd (mshepher@yorku.ca)
Hartmann, 1975; Hirota, 1976). Observations of an eastward traveling wave 2 with a period of $\sim 10-20$ days in the Southern Hemisphere stratosphere in winter and spring were also reported by Venne (1980), Mechoso and Hartman (1982), Venne and Stratford (1979, 1982), Prata (1984), Mechoso et al. (1988), Hirota (1988), Shiotani et al. (1990), Manney et al. (1991), Fishbein et al. (1993), to mention a few. Some westward propagating free Rossby waves have also been observed (Rodgers, 1976; Hirota, 1975, 1976; Mechoso and Hartmann, 1982; Hirota and Hirooka, 1984). It was suggested that the source of these eastward propagating waves is instability associated with their relation to the seasonal evolution of the mean zonal winds field (Hirota, 1976; Hatmann, 1979, 1983; Hirota et al., 1990; Shiotani et al., 1993).

In contrast, the Nimbus observations revealed that the Southern Hemisphere summer was very quiescent. Model simulations (e.g. Forbes et al., 1995) also supported this pattern. However, medium-scale waves (zonal wavenumbers 4 7) were observed to frequently dominate the Southern Hemisphere summer wind and temperature fields (e.g. Randel and Stanford, 1985a, b, and references therein). It was shown that the Southern Hemisphere summer flow vacillates between periods of highly perturbed states, caused by nonlinear baroclinic instabilities, on one hand, and zonally symmetric states - on the other, with a time scale of 10-20 days.

Recent satellite experiments like the Microwave Limb Sounder (MLS) (Waters et al., 1993) and the Improved Stratosphere and Mesospheric Sounder (ISAMS) (Taylor et al., 1993) on the Upper Atmosphere Research Satellite (Reber et al., 1993), the Sounding the Atmosphere using Broadband Emission Radiometry (SABER) on board the Thermosphere, Ionosphere, Mesosphere Energetics and Dynamics (TIMED) satellite (Russell et al., 1999; Yee, 2003) and the MLS (Waters et al., 2006) on the AURA spacecraft (Schoeberl et al., 2006) have provided global temperature

Published by Copernicus Publications on behalf of the European Geosciences Union. 
observations throughout the middle atmosphere, which have been used to study the global signatures of planetary-scale perturbations including those in the Southern Hemisphere high latitudes (e.g. Hirooka, 2000; Palo et al., 2005; Ern et al., 2007). However, the spatial and temporal coverage of these observations has been restricted by orbit configurations, viewing geometry and vertical resolution. Studies employing model data assimilated fields (temperature, wind and geopotential height) like those provided by the United Kingdom Meteorological Office (UKMO), the National Centre for Environmental Predictions (NCEP) and the European Centre for Medium Range Weather Forecast (ECMWF) still remain the main source of information about the dynamics of the stratosphere, and in particular the Southern Hemisphere stratosphere.

Experiments like the Global Positioning System/Meteorology (GPS/Met) (Ware et al., 1996; Rocken et al., 1997) and the Challenging Minisatellite Payload (CHAMP) (Wickert et al., 2004) have provided a new global high-resolution datasets of temperature, pressure and refractivity profiles in the $1-40 \mathrm{~km}$ altitude range and have successfully been used in the study of short vertical wavelengths and global and regional scale gravity wave activity (Tsuda et al., 2000; Venkat Ratnam et al., 2004; de la Torre et al., 2006), as well as equatorial Kelvin waves (e.g. Tsai et al., 2004; Randel and Wu, 2005; Tsuda et al., 2006; Venkat Ratnam et al., 2006; Baumgaertner and McDonald, 2007; Hei et al., 2008). Temperature observations from the Constellation Observing System for Meteorology, Ionosphere and Climate (COSMIC) GPS satellite constellation (Rocken et al., 2000) have also been successfully used in the study of gravity waves' global distribution (e.g. Alexander et al., 2008a, b).

In the present study we employ COSMIC temperature observations to examine the dynamics of the Southern Hemisphere stratosphere in summer at high latitudes. The analysis is concentrated on the morphology of the temperature field at $30 \mathrm{~km}$ height $(\sim 10 \mathrm{hPa})$ and the decomposition of largescale oscillations with periods between 2 and 30 days. In the following sections we first introduce the COSMIC temperature dataset, and then describe the data analysis procedures used in the spectral decomposition of the oscillations observed. The results obtained are presented and discussed, before summarizing our conclusions.

\section{COSMIC temperature data}

The Constellation Observing System for Meteorology, Ionosphere and Climate (COSMIC)/Formosa Satellite Mission 3 (FORMOSAT-3) (Rocken et al., 2000) was launched on 14 March 2006 on a circular orbit with an inclination of $72^{\circ}$ at an altitude of $512 \mathrm{~km}$ (Cheng et al., 2006). This GPS radiooccultation (RO) constellation mission is a collaborative pro- ject of the National Space Organization (NSPO) in Taiwan and the University Corporation for Atmospheric Research (UCAR) in the United States of America. The COSMIC/FORMOSAT-3 spacecraft constellation consists of six micro-satellites, each carrying an advanced GPS receiver for radio occultation and precision orbit studies. By measuring the phase delay of radio waves from GPS satellites as they are occulted by the Earth's atmosphere, accurate and precise vertical profiles of bending angles of radio waves' trajectories are obtained in the ionosphere, stratosphere and troposphere. From these bending angle measurements profiles of atmospheric refractivity are obtained. Some of the preliminary results from the COSMIC mission have been summarized by Anthes et al. (2008).

Immediately after launch the six micro-satellites were orbiting very close to each other at the initial altitude of $512 \mathrm{~km}$. In the first few months of the mission this provided an opportunity for estimating the precision of the radiooccultation technique through comparisons with the independent measurements of each satellite, but globally led to over-sampling of some regions, while others remained undersampled or not observed at all. Over a period of 17 months after the launch the satellites were gradually positioned at their nominal orbits at $\sim 800 \mathrm{~km}$, with orbital plane separations of $30^{\circ}$. The satellite mission presently provides about 1500-2000 RO global observations of vertical profiles of atmospheric pressure, air density, temperature, and water vapor, as well as ionospheric electron density per day over all local solar times. The best latitude coverage is at middle and high latitudes around $55^{\circ}$ and $80^{\circ}$ latitude in both hemispheres (Rocken et al., 2000).

One of the data products of the COSMIC/FORMOSAT- 3 mission is "dry" temperature profiles, which are computed from the observed refractivity under the assumption that the water vapour pressure is zero. The difference between the dry temperature and the actual (kinetic) temperature in the radio-occultation retrieval is due to the presence of water vapour. Above the tropopause $(\sim 10 \mathrm{~km}$ height at high latitudes) it is assumed that water vapour content is negligible and thus the state of the temperature field in the lower stratosphere can be described by the dry temperature profiles. The original COSMIC data are available at $0.1 \mathrm{~km}$ vertical resolution, but they have an effective vertical resolution of the order of $1 \mathrm{~km}$ in the upper troposphere and the stratosphere. Therefore the original (non-independent) data are interpolated to the approximate real resolution of $1 \mathrm{~km}$. The precision of the COSMIC refractivity is $<0.2 \%$ between 10 and $20 \mathrm{~km}$, and $0.7 \%$ at $30 \mathrm{~km}$ height (Schreiner et al., 2007). The accuracy of the COSMIC derived temperatures is better than $0.5 \mathrm{~K}$.

The data considered in the present report are COSMIC version 2.0 "dry" temperatures at altitudes of $20 \mathrm{~km}$ and $30 \mathrm{~km}$, over the latitude range of $60^{\circ}$ to $75^{\circ}$ in the Southern Hemisphere summer for the period of 1 December 2006 to 1 March 2007 (Day 334, 2006 to Day 60, 2007). 


\section{Data analysis}

The measurements were first binned according to latitude and altitude for each of the days of observations within latitude bands of $5^{\circ}$ and with a height resolution of $1 \mathrm{~km}$. Thus, a given latitude/altitude band in the $55^{\circ} \mathrm{S}-80^{\circ} \mathrm{S}$ range contains all temperature observations within that latitude band with their respective universal times and longitudes, or on average about $60-70$ profiles per day. As was already mentioned, earlier in the mission the orbit planes of the different satellites were in close proximity of each other, which led to non-uniform global spatial and temporal coverage. Therefore a given latitude/longitude was often sampled at different universal times (UT) (and different local solar times) on a given day. In order to reduce the scatter and gaps in the data the observations within each of the $5^{\circ}$-latitude bands and for each of the months considered (December 2006, January and February, 2007) are binned also according to UT with a resolution of 0.5 days $(12 \mathrm{~h})$. With respect to the missing data in longitude the observational gaps are linearly interpolated. Further the data were transformed into a $60 \times 60 \mathrm{mesh}$, preserving the 0.5-day binning grid in UT, and then zonally fitted with a harmonic wave function with wave numbers from 1 to 3 . This procedure serves the purpose of filtering out the data from observation noise and small-scale perturbations. The $60 \times 60$ gridded temperature data $(0.5$ day $\left./ 6^{\circ}\right)(\mathrm{UT} /$ longitude) for each month, latitude band and height were combined to produce Hovmöller diagrams (timelongitude) of the temperature field. The Hovmöller diagrams are often used to investigate the zonal and temporal propagation of specific wave components (Shiotani et al., 1997; Wheeler and Kiladis, 1999; Tsai et al., 2004; Randel and $\mathrm{Wu}, 2005)$. These presentations have revealed the unmistakable presence of planetary-scale periodic perturbations in the COSMIC temperature data consistent with the presence of stationary wave 1 at $30 \mathrm{~km}$ height and at $\sim 0-10^{\circ} \mathrm{E}$, coupled with some other transient waves.

To examine further the amplitude and direction of these perturbations at a given latitude band and height, the data were binned according to longitude and UT and weighted over the number of observations within each bin. After some testing, two binning resolutions in longitude were chosen, in order to obtain sufficient zonal coverage for planetary wave analysis. First, for a preliminary diagnostic, a $40^{\circ}$-binning in longitude was carried out which provided a uniform global coverage without gaps and in spite of being rather coarse, was still sufficient to preserve the main signatures of planetary perturbations with a period greater than 2 days. The second binning format considered a longitudinal grid of $15^{\circ}$; the need for this higher resolution is explained in detail in Sect. 3.2. Thus the data were binned in latitude bands of $5^{\circ}$, longitude bins of $40^{\circ}\left(15^{\circ}\right)$, height bins of $1 \mathrm{~km}$ and UT resolution of 0.5 days $(12 \mathrm{~h})$ and subjected to spectral analysis, the results of which are discussed next.

\subsection{Lomb-Scargle periodograms}

To examine the planetary wave variability in the low stratosphere $(20-40 \mathrm{~km})$ during the period of interest (1 December 2006-1 March 2007), 30-day time segments sliding by one-day intervals were used (similar to Tsai et al., 2004), covering the period from 15 November 2006 to 15 March 2007 (15 days before and after) for each of the latitude/longitude/height/UT bins. The necessity of time segments and the choice of their length for wave decomposition arises from the fact that a planetary wave packet lasts several periods and the time segment should be sufficient to allow for more than one cycle to be examined. Fedulina et al. (2004) concluded that the time segments must be of a minimum length of 70 days in order to isolate planetary waves with periods of about 10-20 days and determine their direction of propagation. Chshyolkova et al. (2006) used a time window with a variable length equaling three times the periods of the wave (e.g. 48-day time window for a 16-day wave with a 4-day step), while Pancheva et al. (2008) successfully used 45-day time intervals with a one-day step to resolve signatures with periods of 23 days and less. All these studies used UKMO assimilated data fields to examine the planetary wave characteristics in the stratosphere. Since the planetary-scale perturbations usually last more than one cycle a 30-day time segment would allow the full resolution of planetary waves with periods of the order of 16 days and less.

The data from each of these 30-day segments were subjected to standard spectral analysis beginning with the LombScargle periodogram with amplitude and phase estimation (Scargle, 1982; Hocke, 1998). The Lomb-Scargle periodogram analysis is in essence a least-mean-square analysis, where the data are modeled by sinusoids for each $40^{\circ}$ longitude bin over the entire 30-day UT grid. This covers an array of 10 longitudes (resolution of $40^{\circ}$ ) and 61 time intervals (resolution of 0.5 days) for each 30-day time segment. The daily periodograms yield the wave parameters e.g. periods, amplitudes and phases, corresponding to the median of the respective 30-day segments thus covering the period of 1 December 2006 (Day 334) to 1 March 2007 (Day 60 or 425, starting 1 January 2006). Here only results from the analysis carried out for the latitude range from $60^{\circ} \mathrm{S}$ to $75^{\circ} \mathrm{S}$ are reported.

\subsection{Planetary wave decomposition}

Because the COSMIC satellite data, as any data from other low-earth-orbiting satellite (e.g. UARS, TIMED, AURA) are asynoptic, i.e. unevenly sampled, they cannot be subjected to standard Fourier transform analysis to extract information on perturbation frequencies present in the observations (Hayashi, 1980; Salby, 1982a, b; Wu et al., 1995). Instead least-square fitting methods are applied (e.g. Wu et al., 1995) 
to estimate the space-time Fourier coefficients for the analysis of large-scale perturbations in the COSMIC temperatures at high Southern latitudes.

Test runs using the $40^{\circ}$ longitudinal binning for the planetary wave decomposition showed that it is too coarse to resolve signatures with same period, but different zonal wave numbers. Therefore the data were binned into $15^{\circ}$-longitude and 0.5-day of UT at each of the selected latitude bands and height levels.

The wave decomposition is performed by a linear $2 \mathrm{D}$ (time-longitude) least-square multiple regression simultaneously fitting of all traveling waves with the periods determined in the Lomb-Scargle periodogram analysis, and zonal wave numbers from -3 to 3 , as well as the first three modes of stationary planetary waves (SPW) with zonal wave numbers 1, 2 and 3, over each of the 30-day segments in order to avoid a possible distortion of the usually weaker traveling waves by the much stronger SPWs (Pancheva et al., 2008; P. Mukhtarov and D. Pancheva, personal communication, 2008). The wave decomposition is performed by fitting a model of the general wave form to the data as:

$$
\begin{aligned}
& T=T_{0}+\sum_{i=1}^{3} \sum_{s=-3}^{3} A_{s i} \cos \left(2 \pi \sigma_{i} t+\frac{2 \pi}{360} s l-\varphi_{s i}\right) \\
& +\sum_{s=1}^{3} B_{s} \cos \left(\frac{2 \pi}{360} s l-\psi_{s}\right)
\end{aligned}
$$

where $t$ is the time in days, starting from 1 December 2006 (Day 334, starting 1 January 2006), $l$ - the longitude in degrees, normalized by $360^{\circ}, \sigma_{i}$ - the investigated wave frequencies $\left(\sigma_{i}=1 / T_{i}\right.$, where $T$ is the wave period of the $i^{\text {th }}$ wave, in days, determined by the Lomb-Scargle periodograms), and $s$ is the zonal wave number (the number of waves along the globe at a given latitude band) from -3 to 3 . Here $T_{0}$ is the background temperature field, including the mean temperature and any other perturbations with wavenumbers and frequencies not considered herein; $A_{s i}$, $\phi_{s i}-$ the amplitudes and phases of the traveling waves, and $B_{s}, \psi_{s}$ - the amplitude and phases of the stationary waves with the respective periods and wave numbers. All these parameters are obtained in the fitting procedure. The cosine terms in Eq. (1) are expressed as time series of sines /cosines of the angle $\left(2 \pi \sigma_{i} t+\frac{2 \pi}{360} s l\right)$, and these sine/cosines are the independent parameters in the least-mean squares fitting. The amplitudes $A_{s i}\left(B_{s}\right)$ and phases $\phi_{s i}\left(\psi_{s}\right)$ are calculated for each $s$ and $\sigma$ from the coefficients $a_{j}, b_{j}$ determined in fitting the sine/cosine terms of the wave form. Then $\mathrm{A}_{s i}\left(\mathrm{~B}_{s}\right)=\sqrt{a_{j}^{2}+b_{j}^{2}}, \varphi_{s i}\left(\psi_{s}\right)=\tan ^{-1}\left(a_{j} / b_{j}\right)$, and $j=1, \ldots N$, where $N=i \cdot \mathrm{s}+3$. More detailed description of the procedure can be found elsewhere (e.g. Wu et al., 1995; Pogoreltsev et al., 2002).

The phase of the traveling waves is defined as the time of the wave maximum at zero longitude, while the phase of the stationary waves is defined as the longitude of the wave crest (maximum). Following the established convention, positive wave numbers describe westward propagation, while negative wave numbers - eastward propagation.

\section{Results}

Composite plots of the COSMIC temperature data as a function of longitude over the period of Day 334-425 (1 December 2006-1 March 2007) at 20, 25, 30, 35 and $40 \mathrm{~km}$ revealed the presence of a distinct perturbation which developed over time to what appears as a wave 2, most distinct at the lower altitudes in Dicember. Figure 1a-f shows an example of such a composite plot for each of the three months at $20 \mathrm{~km}$ (left column) and $30 \mathrm{~km}$ (right column) height and $60^{\circ} \mathrm{S}$ latitude; the temperature measurements are given in colour code from purple (beginning of the month) to red (the end of the month) in solid circles. As can be seen in Fig. 1a, there are two distinct crests in the zonal distribution of the perturbations at $20 \mathrm{~km}$, at $\sim 80^{\circ} \mathrm{E}$ and $\sim 280^{\circ} \mathrm{E}$. At the higher altitude earlier in December the perturbations are more transient with maxima around $10^{\circ} \mathrm{E}$ and $240^{\circ} \mathrm{E}$, but with time return to the position seen at $20 \mathrm{~km}$. Over the following two months (January, February, 2007) the perturbations are considerably smaller in magnitude and with not much zonal variability (Fig. 1c-f).

Figure 2a,b gives the spatial and temporal distribution of the temperature field at $20 \mathrm{~km}$ and $30 \mathrm{~km}$ height in December from $60^{\circ} \mathrm{S}$ to $75^{\circ} \mathrm{S}$. The wave perturbations initially seen in the "raw" data in Fig. 1a are now clearly visible illustrating both the complex dynamical structure at each of the latitude bands considered, as well as the variability in the magnitude of these structures with latitude and height. At $20 \mathrm{~km}$ (Fig. 2a) the largest perturbations take place in the first half of the month and are manifested by a signature with two peaks at $\sim 100^{\circ} \mathrm{E}$ and $300^{\circ} \mathrm{E}$ consistent with a wave 2 . Both peaks appear relatively stationary over the latitude range, while a wave 1 can be seen around the middle of December, propagating eastward (phase increasing with time), most evident at $70^{\circ} \mathrm{S}$ and $75^{\circ} \mathrm{S}$. At $30 \mathrm{~km}$ (Fig. 2b) the phase of the wave 2 perturbation at the beginning of December appears shifted westward by about $40^{\circ}-50^{\circ}$, with peaks at $0^{\circ}-10^{\circ} \mathrm{E}$ and $180^{\circ}-200^{\circ} \mathrm{E}$.

The Hovmöller diagrams expressed in terms of residual temperatures, $d T_{\mathrm{obs}}$, at $20 \mathrm{~km}$ and for latitudes from $60^{\circ} \mathrm{S}$ to $75^{\circ} \mathrm{S}$ are shown in Fig. 3a-d. Here $d T_{\text {obs }}$ is the difference between the observation and the zonal mean value of all available temperature observations within the $5^{\circ}$ latitude band over the 92 days considered, $\left.d T_{\mathrm{obs}}=T_{\mathrm{obs}}-T_{\text {mean }}\right)$. The plots show a distinct wave 2 in December. This wave 2 signature appears throughout the period accompanied by another stationary wave 1 perturbation at $\sim 10^{\circ} \mathrm{E}$ during January/February, 2007. All these perturbations show a distinct eastward propagation (increasing phase with time) most apparent in January and February, after Day 370 (e.g. Fig. 3a). 

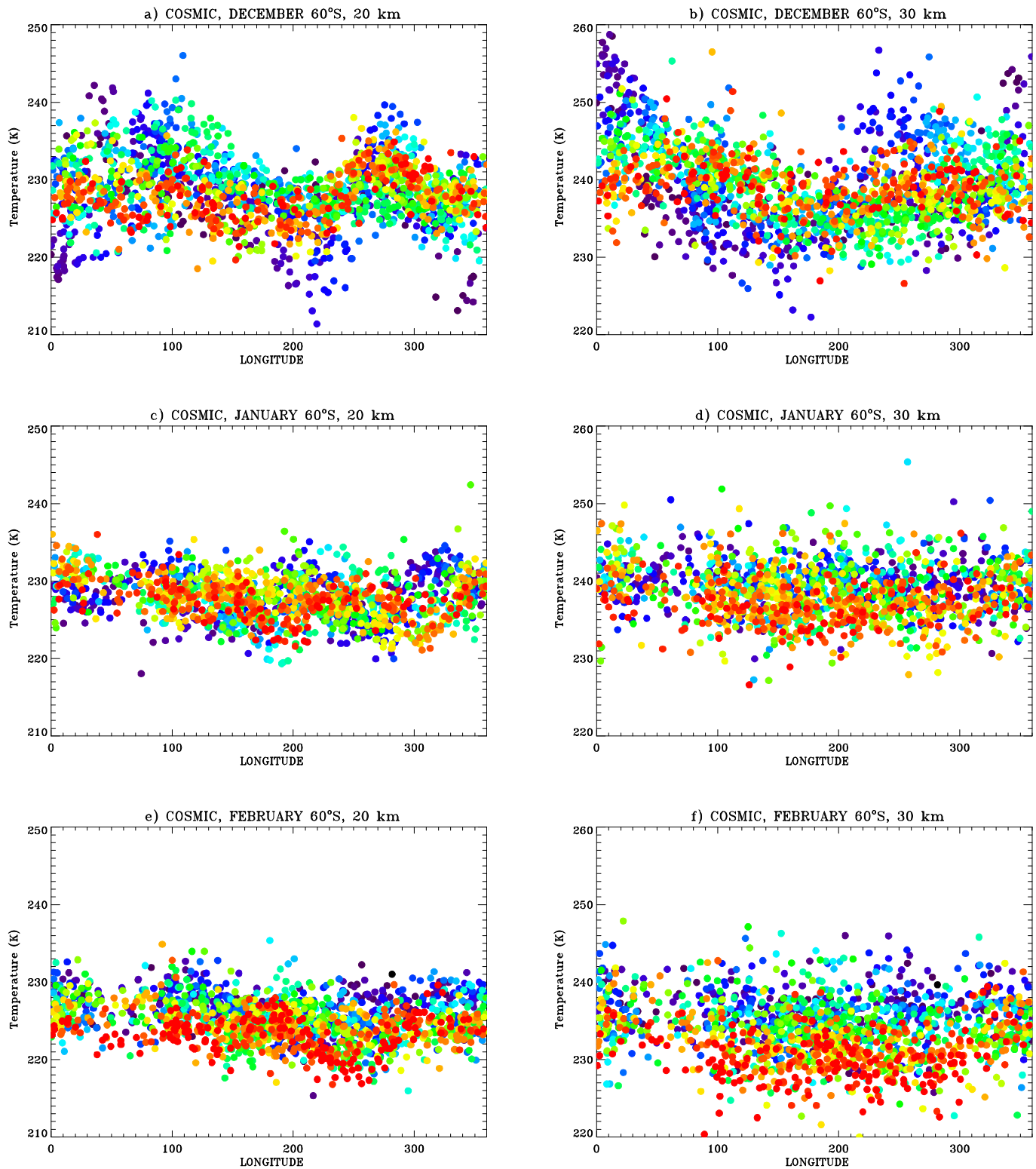

Fig. 1. COSMIC temperature data at $60^{\circ} \mathrm{S}$ and $20 \mathrm{~km}$ (left column) and $30 \mathrm{~km}$ (right column) height for: (a, b) December 2006 ; (c, d) January 2007, and (e, f) February 2007, as a function of longitude. The temperature measurements are given in colour code from purple to red (solid circles) for the beginning to the end of each month.

At $30 \mathrm{~km}$ (Fig. 4a-d) a wave 1 eastward propagating perturbation is observed throughout December 2006 and early January 2007 (Days 334-370) with a peak around $30^{\circ} \mathrm{E}\left(20^{\circ} \mathrm{W}-\right.$ $\left.50^{\circ} \mathrm{E}\right)$. The perturbation is observed over the latitude range from $60^{\circ} \mathrm{S}$ to $75^{\circ} \mathrm{S}$ and propagates eastward with a phase speed of $8^{\circ}$ day $^{-1}$. Later in the period (after Day 380, 15 January 2007) the perturbation becomes confined between $\sim 30^{\circ} \mathrm{W}$ and $50^{\circ} \mathrm{E}$ with peaks about 20 days apart.

Contour plots of the $40^{\circ}$-bin periodograms obtained for each of the 10 longitude bins, show strong perturbations with periods greater than 5 days and amplitudes often maximizing at periods around 10- and 16 days in December 2006 and the second part of January/February 2007 at all longitudes. Figure 5 illustrates the distinct presence of these perturbations at $65^{\circ} \mathrm{S}, 30 \mathrm{~km}$ height and $40^{\circ} \mathrm{E}$ and $120^{\circ} \mathrm{E}$ longitude. The period of the 16-day wave varies with time between 15 and 20 days, and the amplitude peaks are of $\sim 2 \mathrm{~K}$. A perturbation with a period of about 23-25 days is also observed in December, 2006 (Day 334-365). All these signatures are above the $95 \%$ confidence level. 

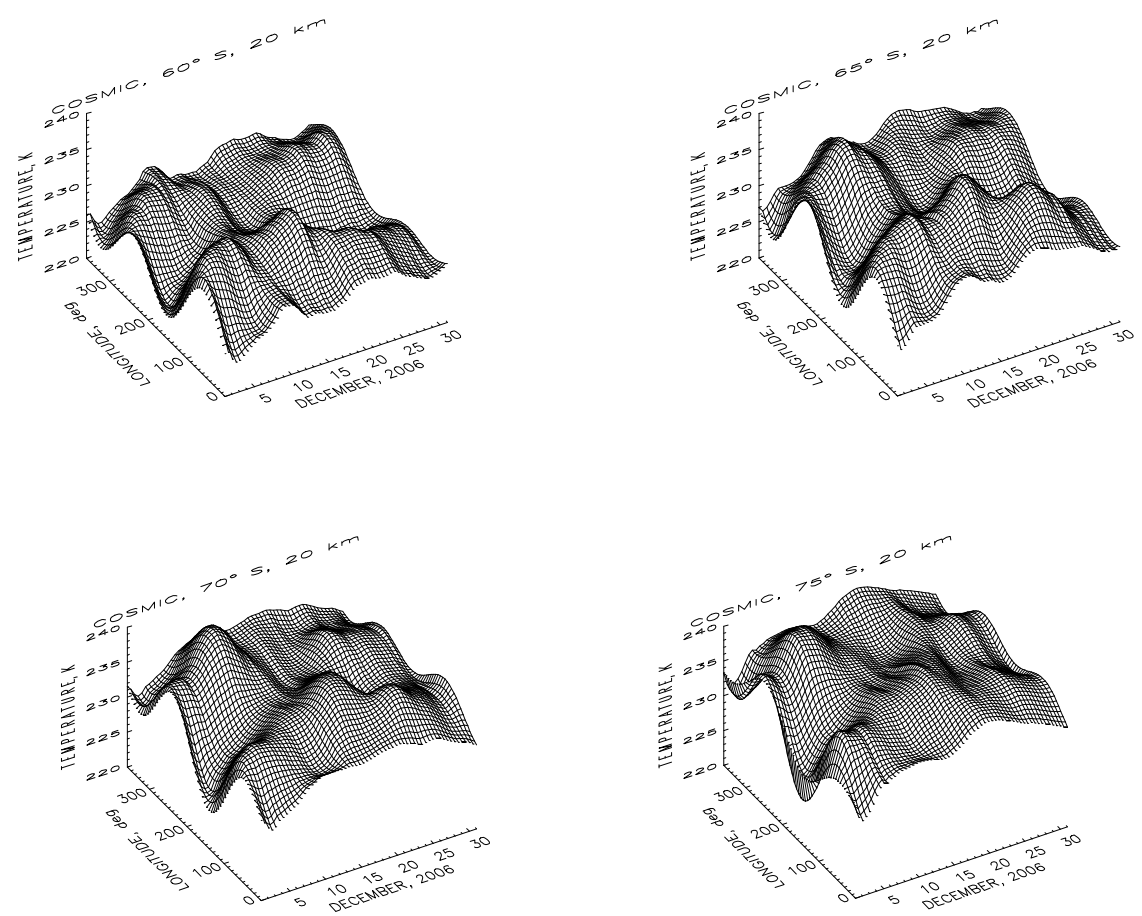

Fig. 2a. Temperature at $20 \mathrm{~km}$ for December 2006 (Day 334-365) from $60^{\circ} \mathrm{S}$ to $75^{\circ} \mathrm{S}$. The perturbations appear to be propagating predominantly eastward, the phase increasing with time (phase defined as the wave maximum).
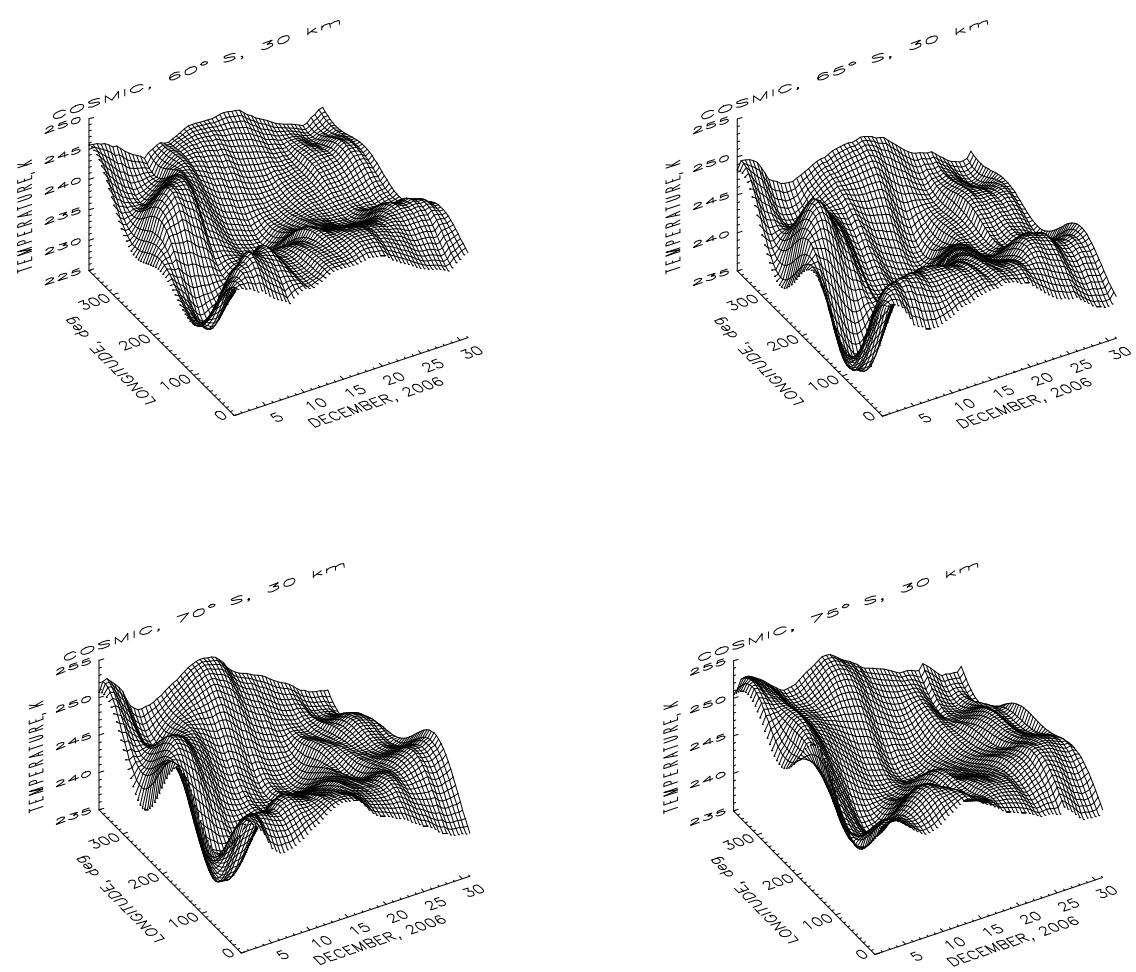

Fig. 2b. Temperature at $30 \mathrm{~km}$ for December 2006 (Day 334-365) from $60^{\circ} \mathrm{S}$ to $75^{\circ} \mathrm{S}$. The perturbations appear to be propagating predominantly eastward, the phase increasing with time (phase defined as the wave maximum). 

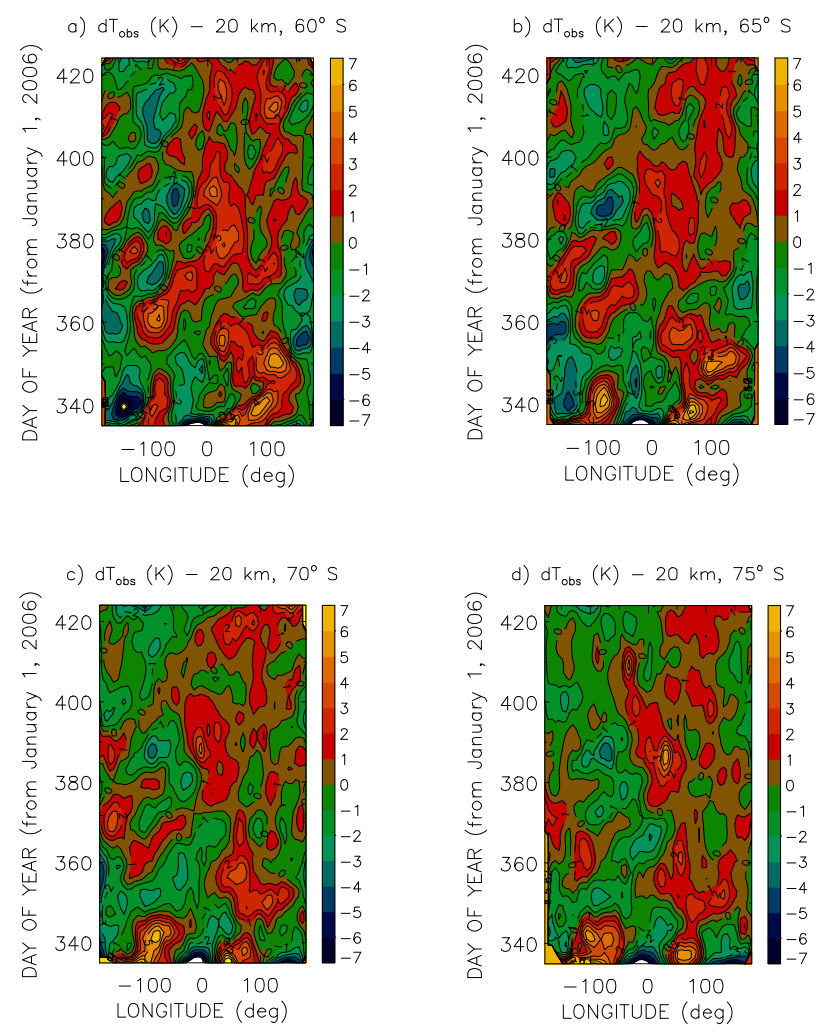

Fig. 3. Hovmöller diagrams of the residual temperatures, $d T_{\mathrm{obs}}$ ( $T_{\mathrm{obs}}-T_{\text {mean }}$ ), in Kelvin, at $20 \mathrm{~km}$ height and from $60^{\circ} \mathrm{S}$ to $75^{\circ} \mathrm{S}$.

An interesting feature is the appearance and the regularity in the periods of these perturbations, particularly in the second half of January and February, seen also at the other latitude bands, not shown here. The amplitude of the perturbations varies with longitude but their presence in the temperature field is easy to identify, with the 16-day and 10-day waves often comparable in magnitude and amplitudes of the order of $1.5-2 \mathrm{~K}$. The amplitude peaks with periods of $\sim 30$ days are likely related to the length of the time segments used in the Lomb-Scargle analysis and are not discussed here.

The Hovmöller diagrams (Figs. 3 and 4) and the LombScargle periodogram analysis showed that for most cases the eastward propagating 16-day and 10-day waves are the dominant waves accompanied by a stationary wave 1 during the period of Day 380-Day 425 (15 January-1 March 2007). In addition, the Lomb-Scargle periodograms revealed a strong perturbation with a period of $\sim 23$ days in December, and some intermittent appearances throughout the rest of the period.

The 2D spectral decomposition revealed the presence of both eastward and westward propagating 10-, 16- and 23-day oscillations with larger eastward amplitudes in December 2006, while stronger westward components were obtained in the second part of the period, (after Day 380, 15 January 2007), as can be seen in Fig. 6 at $65^{\circ}$ S. A strong stationary
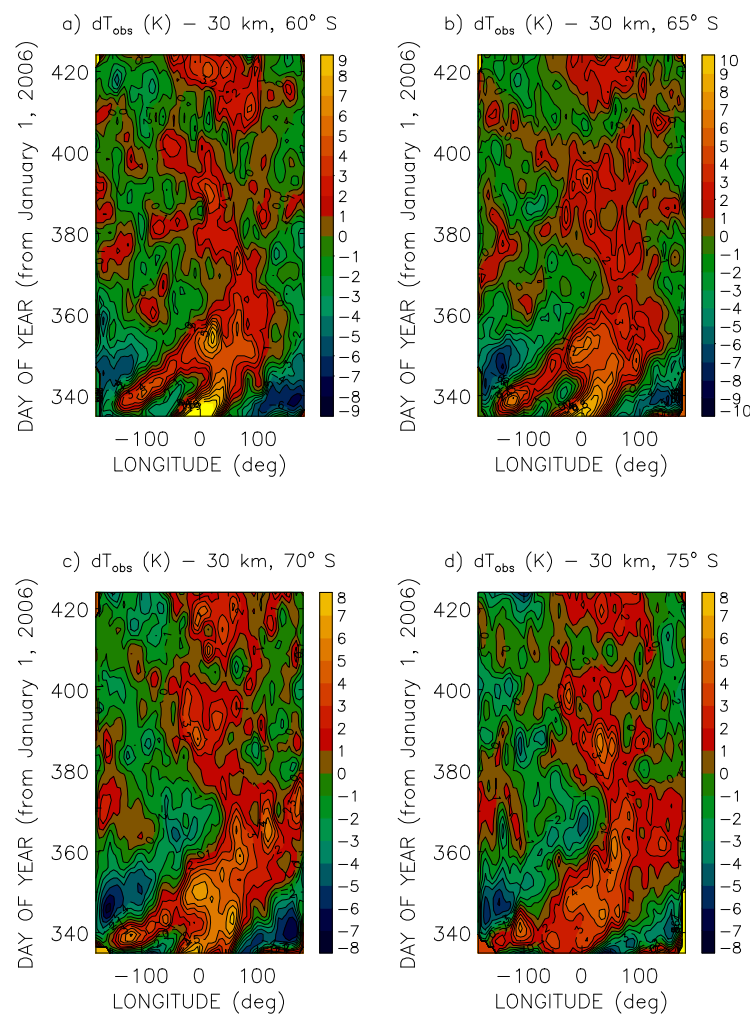

Fig. 4. Hovmöller diagrams of the residual temperatures, $d T_{\mathrm{obs}}$ ( $\left.T_{\mathrm{obs}}-T_{\text {mean }}\right)$, in Kelvin, at $30 \mathrm{~km}$ height and from $60^{\circ} \mathrm{S}$ to $75^{\circ} \mathrm{S}$.

wave 1 was also present. The 30-day time segments used in the analysis are sufficient to track two cycles of a 16-day oscillation, but a 23-day oscillation might not be fully resolved and therefore the results concerning this oscillation might not be conclusive.

From the westward travelling waves, the 16-day wave peaks around Days 347, 360 and 380, while the 23-day oscillation in the first half of the period (334-380) is comparable with the 16-day in amplitude, but later becomes the strongest of the three, although with an amplitude of $\sim 1 \mathrm{~K}$. The errors of the estimated amplitudes are less than $0.1 \mathrm{~K}$ and thus are not shown in the plots of Fig. 6 .

As to be expected the stationary waves with wave 1 and wave 2 dominate the spectrum with the largest amplitudes in December 2006; another, much weaker peak is observed at the end of January, around Day 390.

The planetary wave parameters determined in the 2D spectral analysis are now used to model the temperature field at 20, 25, 30, 35 and $40 \mathrm{~km}$ height over the 1 December 2006-1 March 2007 observation period and at the latitude range from $60^{\circ} \mathrm{S}$ to $75^{\circ} \mathrm{S}$ in order to verify the oscillations derived.

Considering only oscillations with wave numbers from -2 to 2 , but without $s=0$ (i.e. no contribution from zonally symmetric waves) and wave periods of 10,16 and 23 days, the modeled temperature field, $d T_{\text {model }}$, is calculated using Eq. (1) for the universal times and longitudes of the original 
a) LS PERIODOGRAM - AMPLITUDE (K), ALT = $30 \mathrm{KM}$ COSMIC Temperature $\left(65^{\circ} \mathrm{S}, 40^{\circ} \mathrm{E}\right)$

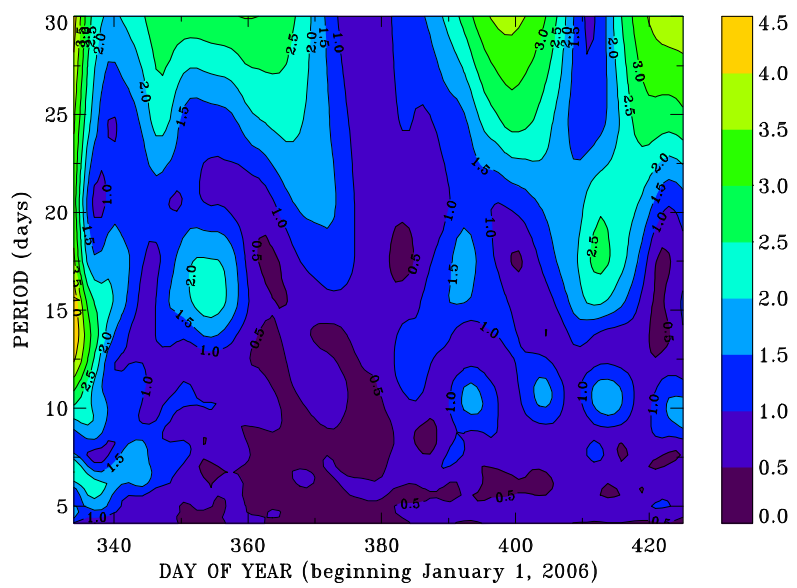

b) LS PERIODOGRAM - AMPLITUDE (K), ALT = $30 \mathrm{KM}$ COSMIC Temperature $\left(65^{\circ} \mathrm{S}, 120^{\circ} \mathrm{E}\right)$

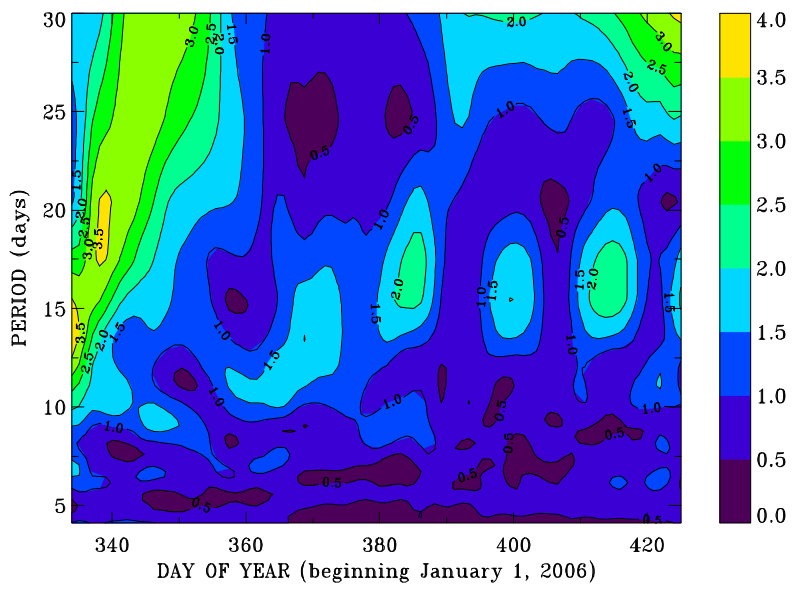

Fig. 5. Contour plots of the Lomb-Scargle periodograms with amplitude and phase determination at $65^{\circ} \mathrm{S}$ latitude band and $30 \mathrm{~km}$ height for the period of Day 334 to Day 425 (1 December 2006-1 March 2007): (a) $40^{\circ} \mathrm{E}$; (b) $120^{\circ} \mathrm{E}$.

observations shown in Figs. 3 and 4 without the $T_{0}$ term. The Hovmöller diagrams of the restored temperature field at $60^{\circ} \mathrm{S}$ to $75^{\circ} \mathrm{S}$ are shown in Fig. 7. The large perturbation seen in Fig. 4a-d, between Day $340-370$ and $30^{\circ} \mathrm{W}-50^{\circ} \mathrm{E}$, is well captured both in terms of its magnitude and spatial extent. The signature propagates eastward with an amplitude of $\sim 5 \mathrm{~K}$. For the rest of the period the model captures the general pattern of the perturbation with a stationary wave 1 , centred around $0-10^{\circ} \mathrm{E}$ with peaks around Days 390-400 and 425 . The agreement between model and raw data illustrated by Fig. 7 was achieved without accounting for zonally symmetric waves (planetary waves with $s=0$ ).

In an attempt to give a quantitative measure of the modeled results the percentage error between the observation residu- als $d T_{\text {obs }}$ as defined earlier and the modeled residuals $d T_{\text {model }}$ were calculated for the coordinates of the observations and the results are shown in Fig. 8. With the exception of a few outliers in the raw data most of the percentage errors fall below $100 \%$, or is less than a factor of 2 .

We remind the reader that the observation temperature residuals $d T_{\text {obs }}$ still contain contributions from all observed perturbations even after the subtraction of the seasonal zonal mean, while the modeled residual $d T_{\text {model }}$ is only from the harmonics with the selected periods and wavenumbers.

This difference in the magnitude of the observed and modeled perturbations results to a great extent from the fact that while the data shown in Fig. 3 are binned only in UT and represent all measurements available from Day 334 to Day 425 (1 December 2006-1 March 2007), the data which eventually produced the least mean square fits and the plots in Fig. 7 were also further binned and weighted over every $15^{\circ}$ longitude bin, before being over-sampled to create a $60 \times 60$ bin grid in UT/longitude used in the $2 \mathrm{D}$ wave decomposition. The amplitudes obtained here are greater than those determined from the Lomb-Scargle analysis applied over the $40^{\circ}$-longitude bins, which further supports the argument that the differences between observations and model as quantified by the percentage error are due to the data binning prior to the spectral decomposition.

Finally the periods of the 10-, 16- and the 23-day waves can vary within a range of 7-11 days for the 10-day wave, 12-20 days for the 16-day wave, and 22-27 days for the 23-day wave (Salby, 1981, 1984). The plots of the 30-day Lomb-Scargle periodograms, samples of which were shown in Fig. 5, also indicate variability with latitude/time of the respective periods although within relatively smaller ranges of 9-11 days, 15-18 days and 22-27 days, respectively.

With this in mind the planetary wave parameters obtained are considered to give a faithful representation of the main dynamical perturbations seen from $60^{\circ} \mathrm{S}$ to $75^{\circ} \mathrm{S}$ over the period of 1 December 2006 to 1 March 2007 (Day 334 to Day 425, starting 1 January 2006).

\section{Discussion}

The analysis of the COSMIC temperature data and the inverse modeling of the observed temperature field revealed the dominant presence of eastward propagating 16- and 23day waves 1 and 2 and stationary wave 1 in December, as well as some westward transient 16- and 23 day waves in the second half of January and February.

Shiotani et al. (1990) examined the presence of eastward wave 2 in geopotential height data at $10 \mathrm{hPa}(\sim 30 \mathrm{~km})$ at $60^{\circ} \mathrm{S}$, for late winter and spring (August-October) and found an eastward wave 2 with a period of 9.2 days, which persisted over a period of almost two months, as well as a wave 1 , at $\sim 180^{\circ} \mathrm{E}$ with a period of $\sim 10$ days. An eastward wave 3 , similar to wave 2 and with same phase speed was 

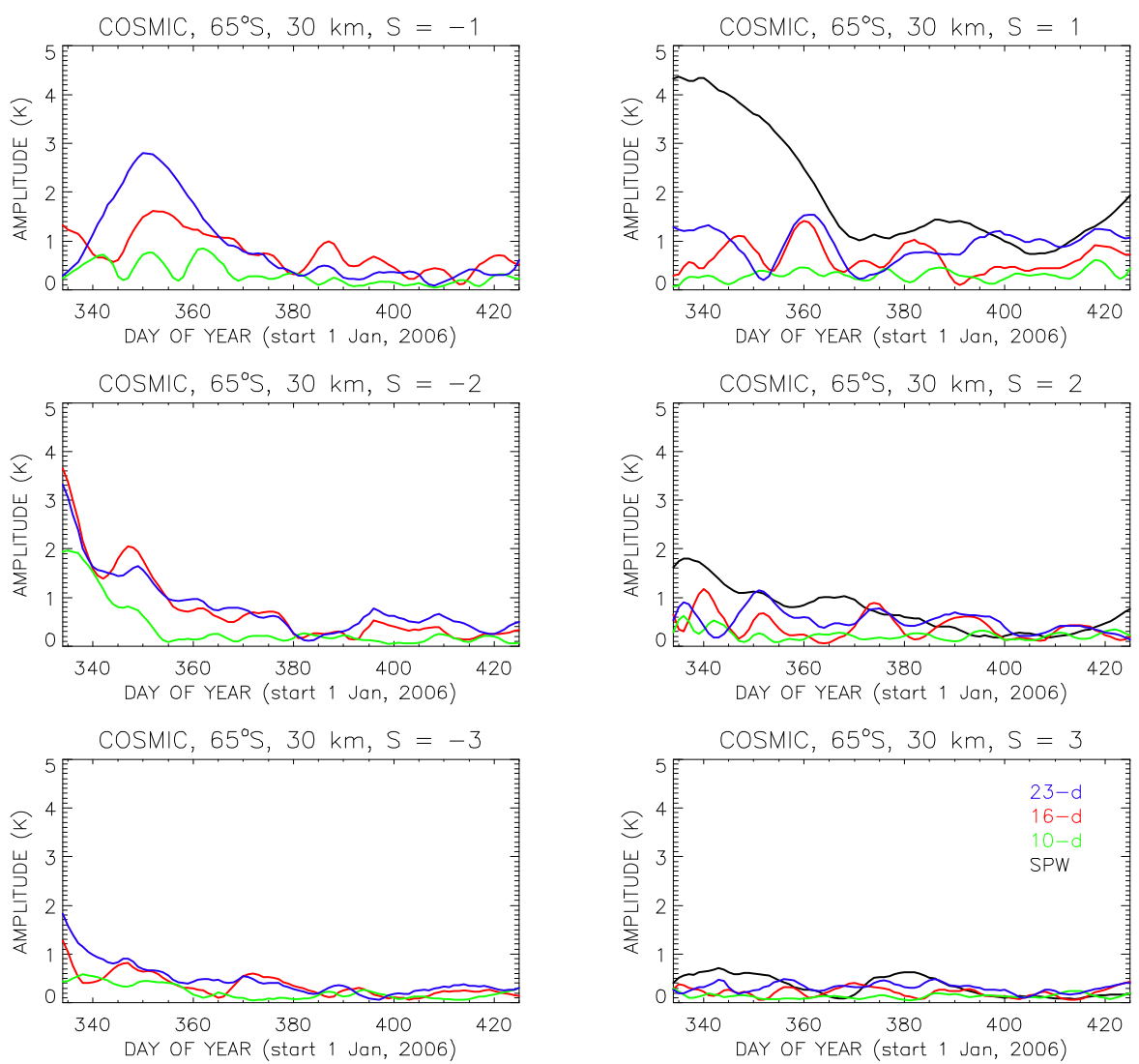

Fig. 6. Amplitudes of the large-scale perturbations at $30 \mathrm{~km}$ altitude for the period from Day 334 to Day 425 (1 December $2006-1 \mathrm{March}$ 2007) for the eastward (left column) and westward (right column) at the $65^{\circ} \mathrm{S}$. The 10-day wave is in green; the 16-day wave - in red; the 23-day wave - in blue, and the stationary planetary wave (SPW) - in black.

also observed. The authors concluded that a wave system moved eastward at a rate of $180^{\circ}$ in 10 days and suggested that eastward traveling wave 2 with a period of $\sim 10$ days was the result of interaction between the stationary wave 1 and the eastward traveling wave 2. Shiotani et al. (1990) also showed that the times of wave- 1 events were related to the phase overlap of wave 1 and wave 2 in such a way that when the wave 1 and wave 2 crests overlap the wave 1 amplitude reaches maximum. It was also suggested that the source of these eastward propagating waves is instability associated with their relation to the seasonal evolution of the mean zonal wind field. The finding of Shiotani et al. (1990) was supported by numerical simulations by Ushimaru and Tanaka (1992) who examined the interaction between wave 1, wave 2 and zonal mean flow and also found that the amplitude of wave 2 is negatively correlated with the amplitude of wave 1 . In many cases the large amplitude of wave 1 occurs only for every two passages of wave 2 over wave 1. Ushimaru and Tanaka (1992) concluded that the interaction between wave 1 and wave 2 causes the periodic variation of wave amplitudes through their energy/entropy exchange and controls the degree of interaction with zonal mean flow through the horizontal phase movement.
Power spectral analysis of temperature observations by the MLS experiment on the UARS by Fishbein et al. (1993) also revealed the presence of a temperature wave 1 and wave 2 at $60^{\circ} \mathrm{S}-75^{\circ} \mathrm{S}$ during a period of minor Stratospheric warming in August/September 1992. The power spectra were typical for the southern winter containing primarily stationary waves and eastward propagating waves consistent with earlier reports (Mechoso and Hartman, 1982; Manney et al., 1991; Shiotani et al., 1993). The MLS analysis showed that wave 1 received most of its power from a stationary wave and a 9day traveling wave, reaching a maximum when the traveling wave had the same phase as the stationary wave. However, the wave 2 had a traveling component similar to that of wave 1 , but did not have a stationary wave component.

Palo et al. (2005) examined the planetary wave dynamics prior to the major stratospheric warming in the winter of 2002 in the Southern Hemisphere employing SABER temperature data. They started from the premise that wave forcing plays a key role in the preconditioning of the atmosphere prior to stratospheric warming and examined the wave interaction between eastward-propagating waves with a period of 10 days, quasi-stationary waves and the zonal mean atmospheric state. The SABER stratospheric temperature data at 

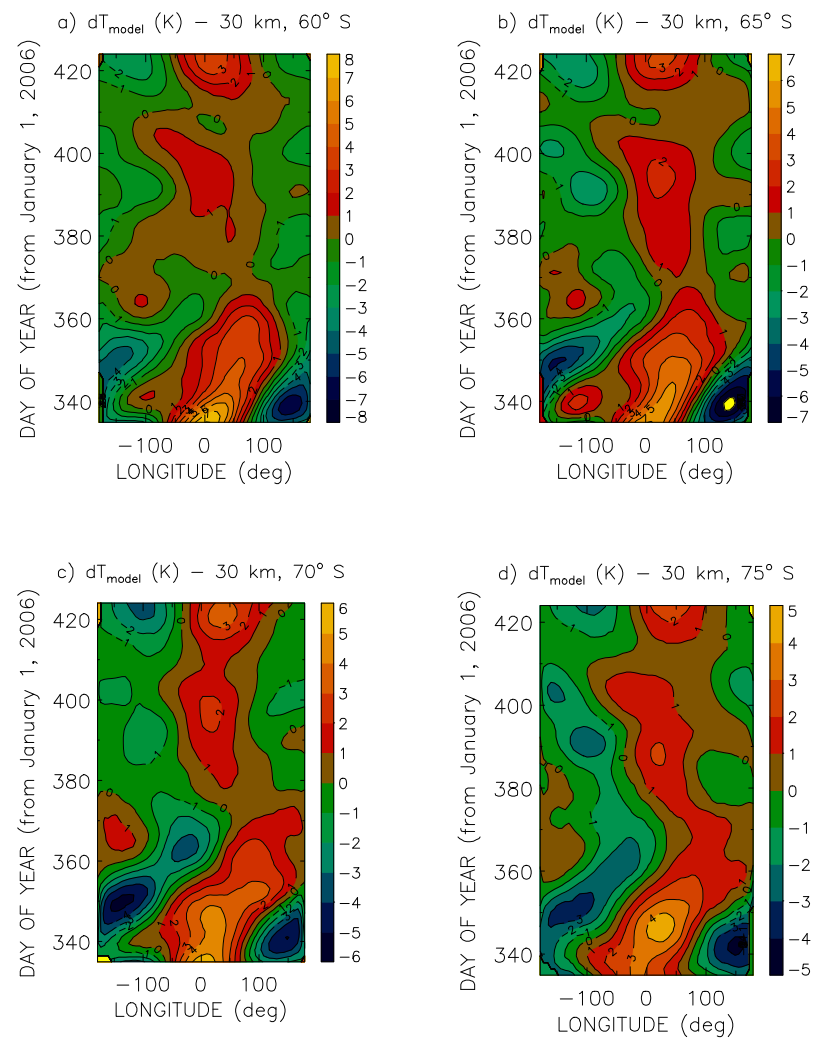

Fig. 7. Hovmöller diagrams of the modeled temperature field at $30 \mathrm{~km}$ height and $60^{\circ} \mathrm{S}, 65^{\circ} \mathrm{S}, 70^{\circ} \mathrm{S}$ and $75^{\circ} \mathrm{S}$ using the planetary wave parameters obtained by the $2 \mathrm{D}$ least-mean-square fitting of the data without zonally symmetric waves. Only traveling planetary waves with wave number \pm 2 and periods of 10,16 and 23 days and stationary planetary waves with wave number 1 and 2 are considered.

$30 \mathrm{~km}$ height revealed a 10-day eastward propagating wave 1, superimposed on a large stationary wave 1 and thus confirmed the earlier report by Shiotani et al. (1993) that the coexistence of a quasi-stationary wave with wave number 1 and eastward propagating waves with periods between 7 and 23 days, usually with a wave number 2 , is a common feature of the winter to early spring in the Southern Hemisphere.

The planetary wave activity with periods of 2-30 days was found to be confined to the Austral winter season and coupled with the eastward flow, but absent in the Austral summer in the wind field at $10 \mathrm{hPa}(\sim 30 \mathrm{~km})$, even when a major stratospheric warming in winter was observed, as in 2002 (Chshyolkova et al., 2006).

Lawrence and Jarvis $(2001,2003)$ observed simultaneous planetary wave oscillations with quasi-periods of 5,10 , and 16 days during the winter between 1997 and 1999 and investigated the planetary wave coupling between the lower and upper Antarctic atmosphere. It was found that a quasi 16day signature with period between 12 and 20 days dominates the winter Antarctic atmosphere throughout the $30-220 \mathrm{~km}$
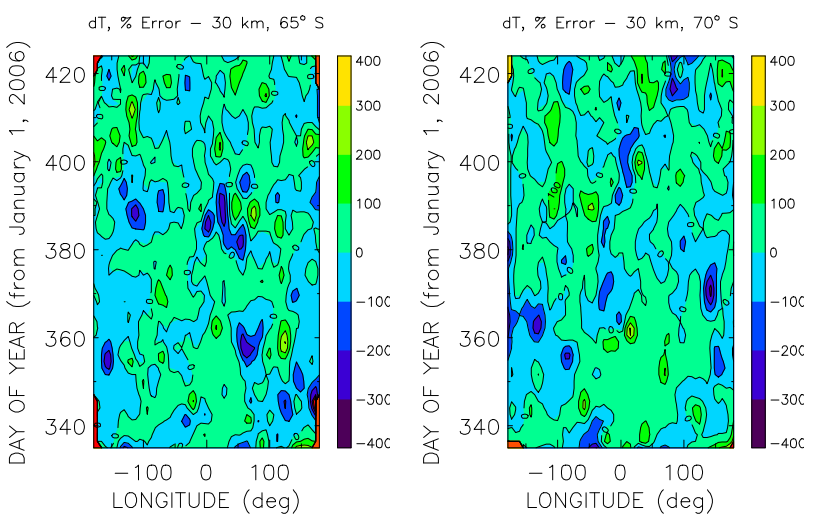

Fig. 8. The percentage error between the restored temperature field and the observations at $65^{\circ} \mathrm{S}$ (left panel) and $70^{\circ} \mathrm{S}$ (right panel) at $30 \mathrm{~km}$ height.

altitude range, with a maximum in the stratosphere and near $60^{\circ} \mathrm{S}$, as was also observed in the present study. The 10 day wave was also found to be the strongest in the winter stratosphere.

All these recent studies (Lawrence and Jarvis, 2001, 2003; Palo et al., 2005; Chshyolkova et al., 2006) consider the stratospheric dynamics during the Antarctic winter and spring seasons, including periods of major stratospheric warmings. Yet, although similar planetary wave signatures are revealed in the COSMIC data, they are for a period when no major stratospheric warming event was registered and for a season when planetary wave activity should be negligible in the Southern Hemisphere (e.g. Hio and Hirota, 2002; Chshyolkova et al., 2006). This poses the question as to the source of these perturbations.

The strong planetary wave activity, including the Austral 16-day wave 1, observed in December 2006 appears to be related to the breaking of the Antarctic polar vortex at the beginning of the month. The intensity of the Antarctic polar vortex is determined by different factors with planetary wave forcing from the troposphere being the major agent. In 2006 the Antarctic polar vortex was very well developed until the beginning of December when it started to be eroded by unusually increasing planetary wave activity. The Antarctic polar vortex breakup occurred on 6 December 2006 (Day 341) and was late in comparison to the long-term mean of Day 329 (25 November) (http://www.cpc.ncep.noaa. gov/products/stratosphere/winter_bulletins/sh_06/). Langematz and Kunze (2008) examined changes of the polar vortex characteristics during spring, including the Antarctic 2006 spring season (September-November 2006) and found that the Antarctic polar vortex was stronger during winter than the Arctic polar vortex and this led to a longer lifetime of the Antarctic vortex and a later transition from spring to summer circulation. Thus the month of December is considered 
to be still representative of spring conditions in the Southern Hemisphere. This explains the more intense planetary wave activity observed at $20 \mathrm{~km}$ (Figs. 1 and 2) compared to that at $30 \mathrm{~km}$ in December and early January. Studies on the influence of equatorial dynamics and in particular of the equatorial QBO on the inter-annual variability at high latitudes have shown that the state of the polar vortex also depends on the phase of the Quasi-Biennial Oscillation (QBO) of the zonal wind in the tropical stratosphere and the level of solar activity (Holton and Tan, 1980, 1982; Labitzke and van Loon, 1988; Gray et al., 2001). In that regard, the cold temperature anomalies and the amplitude of the westward zonal mean wind of the QBO cycle in 2006/2007 were the strongest since 2001

It has been suggested that the inter-annual variations of the 16-day oscillation observed in the Northern Hemisphere are also associated with the equatorial QBO (Espy and Witt, 1996; Espy et al., 1997; Luo et al., 2000). Espy et al. (1997) reported 16-day waves in the summer mesosphere/lower thermosphere (MLT) region $(80-120 \mathrm{~km})$ at $60^{\circ} \mathrm{N}$ only during the westward phase of the equatorial $\mathrm{QBO}$ in the upper stratosphere. These results are consistent with Luo et al. (2002) who showed that these waves are sensitive to the background winds and to a weak QBO modulation.

The period of December 2006-February 2007 was marked by a decrease in the eastward phase of the stratospheric zonal mean wind before reversing to westward in mid-March 2007. In January-February 2007 the equatorial QBO was in its eastward shear phase with the zero zonal mean flow line at $\sim 24 \mathrm{~km}$ height (Alexander et al., 2008b, Fig. 1). Thus, the observed 16-day wave in the COSMIC stratospheric temperatures at the Southern Hemisphere's high latitudes during the westward phase of the equatorial QBO appears similar to Espy et al. (1997)'s summer observations at $60^{\circ} \mathrm{N}$. A 16-day oscillation in the MLT region was also observed at the tropical latitudes $\left(33^{\circ} \mathrm{S}\right)$ in the Southern Hemisphere. Malinga and Poole (2002) reported that the 16-day oscillation appeared strongest during the eastward stratospheric winter jet, but there was also a strong signature during the equinoxes and it could sometimes be found in summer. $\mathrm{Nu}$ merical simulation of the 16-day wave under January conditions by Forbes et al. (1995) confirmed the interpretation that this wave is a result of direct upward propagation into the MLT region.

From all three wave periods considered the traveling 23day wave appeared to be the strongest, but not much is known of its characteristics in the stratospheric temperature field. Studies, involving radar wind observations in the Northern Hemisphere's MLT region (e.g. Luo et al., 2001) have shown that this oscillation correlates with the solar rotation period and climatology, similar to the 16-day wave and is associated with a 25-day oscillation in the F10.7 flux with a time lag of 8-9 days (Pancheva and Mitchell, 2004, Pancheva et al., 2008). Pancheva and Mitchell (2004) identified the 23-day wave as a vertically propagating internal wave with a wave- length of $94-96 \mathrm{~km}$, and confirmed that it is accompanied by a 25-day oscillation of the F10.7 solar flux thus suggesting some dependence on the solar rotation period.

In the stratosphere the 25-day perturbations seen in geopotential height and temperature data were consistent with vertically propagating internal waves associated with radiation flux changes related to the solar activity fluctuations exerting solar forcing on the ozone layer (Ebel et al., 1981, 1986). In view of these studies the 23 day signature in December 2006 could be just the 16-day oscillation.

Although the spectral analyses have given an indication of the possible presence of zonally symmetric waves, $s=0$, they have not been included in the restored temperature field since further analysis is needed including the consideration of the zonal mean zonal winds, a study that will be considered in the future. The very good agreement obtained so far (Figs. 3, 6 , and 7) suggest that the contribution of the zonally symmetric waves to the dynamics of the temperature field observed during the 1 December 2006-1 March 2007 period was not significant.

Although the COSMIC analysis yielded very distinct 16day wave 1 signature and similarities can be drawn between other summer time observations at high latitudes (e.g. Espy et al., 1997; Shiotani et al., 1990) and the results presented herein, it is impossible to further elaborate on the origin of this wave without information on the zonal mean wind field, which will eventually require the employment of data assimilated fields, like those from UKMO and NCEP.

\section{Summary}

The present study examined the global planetary wave structure at the Southern Hemisphere high latitudes in summer, 1 December 2006-1 March 2007, employing new, high resolution temperature data from the COSMIC/FORMOSAT 3 satellite mission.

Eastward traveling waves 1 and 2 with periods of 10 , 16 , and 23 days were identified in the lower stratosphere at $20-40 \mathrm{~km}$ height, which were coupled with strong quasistationary wave 1 and wave 2 . The period of December-early January was dominated by a stationary wave 1 and wave 2 and eastward propagating 10- and 16-day waves, more consistent with the planetary wave activity during late winterspring rather than summer. These summer time temperature perturbations likely result from the longer lifetime of the Antarctic vortex in the spring of 2006 and the later transition from spring to summer circulation.

The results obtained based on the December 2006February 2007 Austral summer season have demonstrated the unique capability of the COSMIC temperature dataset in studying large-scale planetary wave perturbations employing direct observations rather than data assimilated fields for the better understanding of the global stratospheric dynamics and its seasonal variability at high latitudes and in 
particular of the Antarctic region. The seasonal and interannual variability of these temperature planetary wave perturbations are currently examined and will be the subject of a future report.

Acknowledgements. M. S. would like to acknowledge the support of the Research Institute for Sustainable Humanosphere, Kyoto University, where she was a visiting professor. COSMIC data were obtained from the COSMIC Data Analysis and Archive Centre (CDAAC). M.S. thanks S. Alexander, D. Pancheva and P. Mukhtarov for helpful discussions.

Edited by: M. Dameris

\section{References}

Anthes, R. A., Berhardt, P. A., Chen, Y., Cucurull, L., Dymond, K. F., Ector, D., Healy, S. B.,. Ho, S.-P, Hunt, D. C., Kuo, Y.-H., Lio, H., Manning, K., McCormick, C., Meehan, T. K., Randel, W. J., Rocken, C., Schreiner, W. S., Sokolovskiy, S. V., Syndergaard, S., Thompson, D., Trenberth, K. E., Wee, T.-K., Yen, N. L., and Zend, Z.: The COSMIC/FORMOSAT-3 Mission, Bull. Amer. Meteo. Soc., 89, 313-333, 2008.

Alexander, S., Tsuda, T., and Kawatani, T.: COSMIC GPS observations of Northern hemisphere winter stratospheric gravity waves and comparisons with an atmospheric General circulation model, Geophys. Res. Lett., 35, L10808, doi:10.1029/2008GL033174, 2008a.

Alexander, S., Tsuda, T., Kawatani, T., and Takahashi, M.: Global distribution of atmospheric waves in the equatorial upper-troposphere and lower stratosphere: COSMIC observations of wave mean flow interactions, J. Geophys. Res., doi:10.1029/2008JD010039, in press, 2008b.

Baumgaertner, A. J. G. and McDonald, A. J.: A gravity wave climatology for Antarctic compiled from Challenging Minisatellite Payload / Global Positioning System (CHAMP/GPS) radio occultations, J. Geophys. Res., 112, D05103, doi:10.1029/2006JD007504, 2007.

Chapman, W. A., Cross, M. J., Flower, D. A., Peckham, G. E., and Smith, S. D.: A spectral analysis of global atmospheric temperature fields observed by the selective chopper radiometer on the Nimbus 4 satellite during the year 1970-1, Proc. R. Soc. Lond. A, 338, 57-76, 1974.

Cheng, C.-Z, Kuo, Y.-H., Anthes, R. A., and Wu, L.: Satellite constellation monitors global and space weather, Eos, Trans. Amer. Geophys. Union, 87, 166-167, 2006.

Chshyolkova, T., Manson, A. H., Meek, C. E., Avery, S. K., Thorsen, D., MacDougall, J. W., Hocking, W., Murayama, Y., and Igarashi, K.: Planetary wave coupling processes in the middle atmosphere (30-90 km): A study involving MetO and MFR data, J. Atmos. Sol. Terr. Phys., 68, 353-368, 2006.

de la Torre, A., Schmidt, T., and Wickert, J.: A global analysis of wave potential energy in the lower stratosphere derived from 5 years of GPS radio occultation data with CHAMP, Geophys. Res. Lett., 33, L25809, doi:L10.1029/2006GL027696, 2006.

Ebel, A., Schwister, B., and Labitzke, K.: Planetary wave and solar activity in the stratosphere between 50 and 10 mbar, J. Geophys. Res., 86(C10), 9729-9738, 1981.
Ebel, A., Dameris, M., Hass, H., Manson, A. H., Meek, C. E., and Petzoldt, K.: Vertical change of the response to solar activity oscillations with periods around 13 and 27 days in the middle atmosphere, Ann. Geophys., 4, 271-280, 1986, http://www.ann-geophys.net/4/271/1986/.

Ern, M., Preusse, P., Krebsbach, M., Mlynczak, M. G., and Russell III, J. M.: Equatorial wave analysis from SABER and ECMWF temperatures, Atmos. Chem. Phys., 8, 845-869, 2008, http://www.atmos-chem-phys.net/8/845/2008/.

Espy, P. and Witt, G.: Observations of a quasi 16-day oscillation in the polar summer mesospheric temperature, Geophys. Res. Lett., 23, 1071-1074, 1996.

Espy, P. J., Stegman, J., and Witt, G.: Interannual variations of the quasi-16-day oscillation in the polar summer mesospheric temperature, J. Geophys. Res., 102(D2), 1983-1990, 1997.

Espy, P. J., Hibbins, R. E., Jones, G. O. L., Riggin, D. M., and Fritts, D. C.: Rapid, large-scale temperature changes in the polar mesosphere and their relationship to meridional flows, Geophys. Res. Lett., 30(5), 1240, doi:10.1029/2002GL016452, 2003.

Fedulina, I. N., Pogoreltsev, A. I., and Vaughan, G.: Seasonal, interannual and short-term variability of planetary waves in Met Office stratospheric assimilated fields, Q. J. R. Meteorol. Soc., 130, 2445-2458, doi:10.1256/qj.02.200, 2004.

Fishbein, E. F., Elson, L. S., Froidevaux, L., Manney, G. L., Read, W. G., Waters, J. W., and Zurek, R. W.: MLS observations of stratospheric waves in temperature and $\mathrm{O}_{3}$ during the 1992 Southern winter, Geophys. Res. Lett., 20(12), 1255-1258, 1993.

Forbes, J. M., Hagan, M. E., Miyahara, S., Vial, F., Manson, A. H., Meek, C. E., and Portniagin, Y. I.: Quasi 16-day oscillation in the mesosphere and lower thermosphere, J. Geophys. Res., 100, 9149-9163, 1995.

Gray, L. J., Phipps, S. J., Dunkerton, T. J., Baldwin, M. P., Drysdale, E. F. and Allen, M. R.: A data study of the influence of the equatorial upper stratosphere on Northern-Hemisphere stratospheric warmings, Q. J. R. Meteorol. Soc., 127, 1985-2003, 2001.

Hartmann, D. L.: The structure of the stratosphere in the Southern Hemisphere during the late winter 1973 as observed by satellite, J. Atmos. Sci., 33, 1141-1154, 1974.

Hartmann, D. L.: Stationary planetary waves in the Southern Hemisphere, J. Geophys. Res., 82, 4930-4934, 1977.

Hartman, D. L.: Baroclinic instability of realistic zonal-mean states to planetary waves, J. Atmos. Sci., 36, 2336-2349, 1979.

Hartmann, D. L., Mechoso, C. R., and Yamazaki, K.: Observations of wave-mean flow interaction in the Southern Hemisphere, J. Atmos. Sci., 41, 351-362, 1984.

Hayashi, Y.: A method of estimating single-time spectra from polarorbiting satellite data, J. Atmos. Sci., 37, 1385-1392, 1980.

Hei, H., Tsuda, T., and Hiroka, T.: Characteristics of atmospheric gravity wave activity in the Polar regions revealed by GPS radio occultation data with CHAMP, J. Geophys. Res., 113, D04107, doi:10.1029/2007JD008938, 2008.

Hio,Y. and I. Hirota: Interannual variations of planetary waves in the Southern Hemisphere stratosphere, J. Meteor. Soc. Japan, 80(4B), 1013-1027, 2002.

Hirota, I.: Spectral analysis of planetary waves in the summer stratosphere, J. Meteor. Soc., Japan, 53, 33-44, 1975.

Hirota, I.: Seasonal variation of planetary waves in the stratosphere observed by the Nimbus 5 SCR, Quart. J.R. Met. Soc., 102, $757-$ 770,1976 
Hirooka, T.: Influence of normal mode Rossby waves on the mean field: interference with quasi-stationary waves, J. Atmos. Sci., 43, 2088-2097, 1986.

Hirooka, T.: Normal mode Rossby waves as revealed by UARS/ISAMS observations, J. Atmos. Sci., 57, 1277-1285, 2000.

Hirooka, T. and Hirota, I.: Normal mode Rossby waves observed in the upper stratosphere - Part 2: Second antisymmetric and symmetric modes of zonal wave numbers 1 and 2, J. Atmos. Sci., 42, 536-548, 1985.

Hirota, I. and Hirooka, T.: Normal mode Rossby waves observed in the upper stratosphere - Part 1: First symmetric modes of wavenumbers 1 and 2, J. Atmos. Sci., 41, 1253-1267, 1984.

Hocke, K.: Phase estimation with the Lomb-Scargle periodogram method, Ann. Geophys, 16, 356-358, 1998.

Holton, J. and Tan, H.: The influence of the equatorial QuasiBiennial Oscillation on the global circulation at $50 \mathrm{mb}$, J. Atmos. Sci., 37, 2200-2208, 1980.

Holton, J. and Tan, H.: The quasi-biennial oscillation in the Northern Hemisphere lower stratosphere, J. Meteorol. Soc. Jpn, 60, 140-148, 1982.

Labitzke, K. and van Loon, H.: Associations between the 11-year solar cycle, the QBO and the atmosphere - Part 1: The troposphere and stratosphere in the northern hemispehere winer, J. Atmos. Terr. Phys., 50., 197-206, 1988.

Langematz, U. and Kunze, M.: Dynamical Changes in the Arctic and Antarctic stratosphere during spring, Climate Variability and Extremes during the Past 100 Years, edited by: Bronnimann, S., Luterbach, T., Ewen, T., et al., Springer, 293-301, 2008.

Lawrence, A. R. and Jarvis, M. J.: Initial comparisons of planetary waves in the stratosphere, mesosphere and ionosphere over Antarctica, Geophys. Res. Lett., 28, 203-206, 2001.

Lawrence, A. R. and Jarvis, M. J.: Simultaneous observations of planetary waves from 30 to $220 \mathrm{~km}$, J. Atmos. Solar Terr. Phys., 65, 765-777, 2003.

Luo, Y., Manson, A. H., Meek, C. E., Igarashi, K., and Jacobi, C.: Extra-long (20-40 day) oscillations in the mesosphere and lower thermospheric winds: Observations in Canada, Europe and Japan, and considerations of possible solar influence, J. Atmos. Sol. Terr. Phys., 63, 835-852, 2001.

Luo, Y., Manson, A. H., Meek, C. E., Meyer, C. K., Burrage, M. D., Fritts, D. C., Hall, C. M., Hocking, W. K., MacDougall, J., Riggin, D. M., and Vincent, R. A.: The 16-day planetary waves: multi-MF radar observations from the arctic to the equator and comparison with the HRDI measurements and the GSWM modeling results, Ann. Geophys., 20, 691-709, 2002, http://www.ann-geophys.net/20/691/2002/.

Malinga, S. B. and Poole, L. M. G.: The 16-day variation in the mean flow at Grahamstown $\left(33.3^{\circ} \mathrm{S}, 26.5^{\circ} \mathrm{E}\right)$, Ann. Geophys., 20, 2027-2031, 2002, http://www.ann-geophys.net/20/2027/2002/.

Manney, G., Farrara, J., and Mechoso, C.: The behaviour of wave 2 in the Southern Hemisphere stratosphere during late winter and early spring, J. Atmos. Sci., 48, 976-988, 1991.

Mechoso, C. and Harmann, D.: An observational study of traveling planetary waves in the Southern Hemisphere, J. Atmos. Sci., 39, 1921-1935, 1982.

Palo, S. E., Forbes, J. M., Zhang, X., Russell III, J. M., Mertens, C. J., Mlynczak, M. G., Burns, G. B., Espy, P. J., and
Kawahara ,T. D.: Planetary wave coupling from the stratosphere to the thermosphere during the 2002 Southern Hemisphere pre-stratwarm period, Geophys. Res. Lett., 32, L23809, doi:10.1029/2005GL024298, 2005.

Pancheva, D. V. and Mitchell, N. J.: Planetary waves and variability of the semidiurnal tide in the mesosphere and lower thermosphere over Esrange $\left(68^{\circ} \mathrm{N}, 21^{\circ} \mathrm{E}\right)$ during winter, J. Geophys. Res., 109, A08307, doi:10.1029/2004JA010433, 2004.

Pancheva, D. V., Mukhtarov, P., Mitchell, N. J., Antonov, B., Merzlyakov, E., Singer, W., Murayama, Y., Kawamura, S., Xiong, J., Wang, W., Hocking, W., Fritts, D., Riggin, D., Meek, C., and Manson, A.: Latitudinal wave coupling of the stratosphere and mesosphere during the major stratospheric warming in 2003/2004, Ann. Geophys., 26(3), 467-483, 2008.

Prata, A. J.: The 4-day wave, J. Atmos. Sci., 41, 150-155, 1984.

Randel, W. J. and Stanford, J. L.: An observational study of medium-scale wave dynamics in the Southern hemisphere summer - Part 1: Wave structure and energetics, J. Atmos. Sci., 42(11), 1172-1188, 1985.

Randel, W. J. and J. L. Stanford: An observational study of medium-scale wave dynamics in the Southern Hemisphere summer - Part 2: Stationary-transient wave interference, J. Atmos. Sci., 42(11), 1189-1197, 1985.

Randel, W. J. and Newman, P. A.: The stratosphere in the Southern Hemisphere, in Meteorology of the Southern Hemisphere, edited by: Karoly, D. J. and Vincen, D. G., American Meteor. Soc., 410 pp., 1998.

Randel, W. J. and Wu, F.: Kelvin wave variability near the equatorial tropopause observed in GPS radio occultation measurements, J. Geophys. Res., 110, D03102, doi:10.1029/2004JD005006, 2005.

Reber, C. A., Trevathan, C. E., McNeal, R. J., and Luther, M. R.: The upper atmosphere research satellite (UARS) mission, J. Geophys. Res., 98, 10643-10647, 1993.

Rocken, C., Kuo, Y.-H., Schreiner, W., Hunt, D., Sokolovkiy, S., and McCormick, C.: COSMIC system description, Terr. Atmos. Oceanic Sci., 11(1), 21-52, 2000.

Rodgers, C. D.: Evidence for the five-day wave in the upper stratosphere, J. Atmos. Sci., 33, 710-711, 1976.

Russell III, J. M. , Mlynczak, M. G., Goldley, L. L., Tansock, J., and Espin, R.: An overview of the SABER experiment and preliminary calibration results, Pros. SPIE, 3756, 277-288, 1999.

Salby, M. L.: Rossby normal modes in nonuniform background configuration - Part 2: Equinox and solstice conditions, J. Atmos. Sci., 38, 1837-1840, 1981.

Salby, M. L.: Sampling theory for asynoptic satellite observations - Part 1: Space-time spectra resolution and aliasing, J. Atmos. Sci., 39, 2577-2600, 1982a

Salby, M. L.: Sampling theory for asynoptic satellite observations Part 2: Fast Fourier synoptic mapping, J. Atmos. Sci., 39, 26012614, 1982b.

Scargle J. D.: Studies in aeronomical time series analysis: II Statistical aspects of spectral analysis of unevenly spaced data, Astrophys. J., 263, 835-853, 1982.

Schoeberl, M. R., Douglas, A. R., Hilsenrath, E., et al.: Overview of the EOS AURA mission, IEEE Trans. Geosci. Remote Sens., 44, 1066-1074, 2006.

Schreiner, W., Rocken, C., Sokolovskiy, S., Syndergaard, S., and Hunt, D.: Estimates of the precision of GLS radio occultations 
from teh COSMIC/FORMOSAT-3 mission, Geophys. Res. Lett., 34, L04808, doi:10.1029/2006GL027557, 2007.

Southern Hemisphere winter summary, 2006, Climate Prediction Centre, online: (http://www.cpc.ncep.noaa.gov/products/ stratosphere/winter_bulletins/sh_06/).

Shiotani, M., Kuroi, K., and Hirota, I.: Eastward travelling waves in the Southern Hemisphere stratosphere during the spring of 1983 , Q. J. R. Meteorol. Soc., 116, 913-927, 1990.

Shiotani, M., Shimoda, N., and Hirota, I.: Inter-annual variability of the stratospheric circulation in the Southern Hemisphere, Q. J. R. Meteorol. Soc., 119, 531-546, 1993.

Shiotani, M., Gille, J. G., and Rocher, A. E.: Kelvin waves in the equatorial lower stratosphere as revealed by cryogenic limb array etalon spectrometer temperature data, J. Geophys. Res., 102(D22), 26131-26140, 1997.

Speth, P. and Madden ,R.: Space - time spectral analyses of Northern Hemisphere geopotential heights, J. Atmos. Sci, 40, 10861100, 1982.

Taylor, F. W., Rodgers, C. D., Whitney, J. G., et al.: Remote sensing of atmospheric structure and composition by pressure modulator radiometry from space: The ISAMS experiment on UARS, J. Geophys. Res., 98, 10799-10814, 1993.

Tsai, H. F., Tsuda, T., Hajj, G. A., Wickert, J., and Aoyama, Y.: Equatorial Kelvin waves observed with GPS occultation measurements (CHAMP and SAC-C), J. Met. Soc. Japan, 82(1B), 397-406, 2004.

Tsuda, T., Nishida, M., Rocken, C., and Ware, R. H.: A global morphology of gravity wave activity in the stratosphere revealed by the GPS occultation data GPS/MET, J. Geophys. Res., 105(D6), 7257-7273, 2000.

Tsuda, T., Venkat Ratnam, M., Kozu, T., and Mori, S.: Characteristics of 10-day Kelvin wave observed with radiosondes and CHAMP/GPS occultation during the CPEA campaign (AprilMay, 2004), J. Meteor. Soc. Japan, 84A, 277-293, 2006.

Ushimaru, S. and Tanaka, H.: A numerical study of the interaction between stationary Rossby waves and eastward-traveling waves in the Southern Hemisphere stratosphere, J. Atmos. Sci., 49, 1354-1373, 1992.
Venkat Ratnam, M. V., Tetzlaff, G., and Jacobi, C.: Global and seasonal variations of stratospheric gravity wave activity deduced from the CHAMP/GPS satellite, J. Atmos. Sci., 61(13), 1610 1620, 2004.

Venkat Ratnam, M. V., Tsuda, T., Kozu, T., and Mori, S.: Longterm behaviour of the Kelvin waves revealed by CHAP/GPS RO measurements and their effects on the tropopause structure, Ann. Geophys., 24, 1355-1366, 2006, http://www.ann-geophys.net/24/1355/2006/.

Venne, D. E.: A 4-day winter polar stratosphere wave: Observations and theory. Int. Symp. Middle Atmosphere Dynamics and Trasport, Urbana, Handbook for MAP, Vol. 2, 157-164, 1980.

Venne, D. E. and Stanford, J. L.: Observation of a 4-day temperature wave in the polar winter stratosphere, J. Atmos. Sci., 36, 2016-2019, 1979.

Venne, D. E. and Stanford, J. L.: An observational study of highlatitude planetary waves in winter, J. Atmos. Sci., 39, 10261034, 1982.

Waters, J. W., Froidevaux, L., Harwood, R. S., et al.: The Earth Observing System Microwave Limb Sounder (EOS MLS) on the Aura satellite, IEEE Trans. Geosci. Remote Sens., 44, 10751092, 2006.

Wheeler, M. and Kiladis, G. N.: Convectively coupled equatorial waves: analysis of clouds and temperature in the wave-frequency domain, J. Atmos. Sci., 56, 374-399, 1999.

Williams, C. R. and Avery, S. K.: Analysis of long-period waves using the mesosphere-stratosphere-troposphere radar at Poker Flat, Alaska, J. Geophys. Res., 97, 20855-20861, 1992.

Wu, D. L., Hays, P. B., and Skinner, W. R.: A least squares method for spectral analysis of space-time series, J. Atmos. Sci., 52, 3501-3511, 1995.

Yee, J. H.: TIMED Mission Science Overview, John Hopkins Apl. Technical Digest, 24(2), 136-141, April-June, 2003. 